\title{
Pateta Médico e Pateta Monstro ${ }^{1}$
}

Goofy as Dr. Jekyll and Mr. Hyde

Rodrigo Otávio dos Santos²

\section{RESUMO}

No presente artigo faremos uma análise da adaptação da obra de Robert Louis Stevenson, O médico e o monstro, para os quadrinhos Disney, na série oitentista Pateta Faz História, onde a personagem adapta diversas biografias e personagens literários de forma humorada e anárquica. Com roteiro de Cal Howard, desenhos de Anibal Uzal e Hector Adolfo de Urtiága e arte-final de Rubén Torreiro, a história em quadrinhos coloca a personagem Pateta como a personagem central da trama de Stevenson, tentando transpor com muito humor o texto de terror que Ihe influenciou. As similaridades entre os dos textos serão abordadas neste artigo, bem como as diferenças, ora sutis ora gritantes, entre ambas as obras. Será analisada a criação e personificação das personagens, o quanto a personagem Pateta influencia na personagem Jekyll e o papel do coadjuvante Mickey na trama. Além disso, tentaremos mostrar como os estúdios Disney contornam o terror de Stevenson por meio do humor das personagens e do roteiro estabelecido pelo escritor da história em quadrinhos. Tentaremos mostrar também como o uso do desenho ajuda a colocar os valores de ironia e comicidade no desenrolar da trama. Por fim, faremos nossas considerações finais.

Palavras-chave: Quadrinhos. Literatura. Adaptação.

\section{ABSTRACT}

In this article, we study an adaptation form the Robert Louis Stevenson's novel Strange Case of $\mathrm{Dr}$ Jekyll and Mr Hyde, to Disney`s characters in the eighties series called Pateta faz História, were Goofy adapts several biographies and characters form novels. Written by Cal Howard and illustrated by Anibal Uzal, Hector Adolfo de Urtiága and Rubén Torreiro, the comic book puts Goofy as Dr. Jekyll and Mr. Hyde, with humour. In this article we analise the similarities between the two texts and the diferences between them as well. We will analise the characters, their persona and how many Goofy's personality influences in the plot. Besides, we will try to demonstrate how Disney Studios can humorize the horror novel by Stevenson. In the end of this article, we will show our final considerations.

Keywords: Comics. Literature. Adaptation.

\footnotetext{
${ }^{1}$ Trabalho apresentado no dia 17 de outubro de 2013, no Grupo de Trabalho 11 - Ciência e Tecnologia no Humor Gráfico e nos Quadrinhos.

${ }^{2}$ Doutorando no Programa de Pós Graduação em História da UFPR. Mestre em Tecnologia pelo Programa de Tecnologia da UTFPR. E-mail: rodrigoscama@gmail.com
} 


\section{PATETA MÉDICO E PATETA MONSTRO}

No final da década de 1970, início da de 1980, os estúdios Disney desenvolveram uma série de histórias que adaptavam personagens históricos e romances literários utilizando a personagem Pateta como protagonista das tramas. Era, segundo Ribeiro (2011), a primeira vez que a personagem encarnava o papel de protagonista nos quadrinhos. E, mais interessante, a primeira vez que Mickey, personagem máxima de Walt Disney, desempenhava um papel secundário ou de apoio.

$\mathrm{Na}$ história que pretendemos analisar, criada em 1983, Pateta faz o duplo papel de Dr Jekyll e Mr. Hyde, em uma adaptação do clássico distópico escrito por Robert Louis Stevenson em 1886. É interessante perceber também que os artistas da Disney se valeram de outras adaptações para criar seu Pateta/Jekyll, sendo a principal delas o filme $\mathrm{O}$ Professor Aloprado (The Nutty Professor) dirigido e estrelado por Jerry Lewis em 1963. Neste trabalho, porém, não nos ocuparemos da análise deste filme, passando direto para a referência original que originou as demais adaptações.

Em O Médico e o Monstro, Stevenson busca compreender o lado sombrio do ser humano, além de tentar compreender certos aspectos da psiquê humana e do inconsciente. Suppia (2005) diz que o romance é precursor, ao lado de Frankestein, de Mary Shelley do gênero de ficção científica, e que todos os "cientistas malucos" derivam da linhagem estabelecida pelos doutores Frankestein e Jekyll. Estes cientistas - somados a outras personagens como as de Wells, apontavam para a arrogância humana, bem como para o mau uso da ciência e a consequente degradação humana por meio das obras que ele mesmo criou, como informa lachtechen (2008).

É sempre bom lembrar os prodigiosos avanços da ciência que, no imaginário do momento, estaria madura para desvendar todos os mistérios da natureza. Para Costa e Schwarcz (2007), os homens do período passavam a acreditar no seu domínio sobre a natureza, graças aos seus inventos que abriam novas perspectivas e projeções. Dos inventos básicos aos mais surpreendentes, um novo mundo de novidades descortinava-se aos cidadãos das metrópoles. Há um esquema de representação coletiva elaborado pela sociedade europeia do final do século XIX 
que legitima a ordem vigente, orienta condutas, pauta e hierarquiza valores, assim como estabelece as metas e constrói seus mitos (PESAVENTO, 1997). Stevenson em seu conto de terror tendia ir contra este movimento utópico, imaginando e caracterizando suas personagens com a personificação do malefício que esta tecnologia e seu uso indiscriminado poderia ter.

Já a obra protagonizada por Pateta nada tem de pessimista. Isso porque a personagem Pateta personifica tanto Dr. Jekyll quanto Mr. Hyde de forma muito diferente daquela concebida por Stevenson. Pateta (Goofy, no original), de acordo com Cavalcanti (1977) foi criado por Paul Murry para os estúdios Disney em 1933 para ser o companheiro inseparável da estrela maior da companhia, o ratinho Mickey. Ainda de acordo com o autor, a personagem é um cachorro humanizado, cujas principais características são a simplicidade, a bondade e a estupidez que chega às raias da debilidade mental. Já Mickey, ainda de acordo com Cavalcanti (1977), seria lançado nos quadrinhos em 1930, dois anos depois de sua estreia no cinema, e no período de criação da história em quadrinhos aqui analisada, atuava basicamente como um detetive astuto que além de prender os bandidos também repara as bobagens feitas por Pateta.

Como já dissemos, esta característica de personagem principal/secundário inverte-se nesta coleção criada pelos estúdios Disney, criada sob encomenda da matriz norte-americana para os estúdios do Argentino Jaime Diaz, conforme explica Alencar (2011).

Seus autores são Cal Howard, norte-americano que era roteirista e animador para os estúdios Walter Lantz na década de 1920, até que foi contratado pelos estúdios Disney em 1929. Em sua carreira, trabalhou com diversos pioneiros da animação, como Ub Iwerks e os irmãos Fleischer (inducks.org, 2013). Os desenhos, que formam grande parte da trama da história, foram criados por Hector Adolfo de Urtiága, argentino que trabalhava nos estúdios de Jaime Diaz desde 1975 e que entre outras coisas desenhou também Envidiote e Marilyn Morrón. Trabalhou também para estúdios chilenos, onde ficou conhecido pelos quadrinhos que publicava na editora Zig Zag. Seu companheiro nos pincéis era Horácio Saavedra, também argentino, que trabalhou muitos anos desenhando uma das maiores criações portenhas, Patorozu, nos estúdios de Dante Quinterno. 
A premissa da história torna-se claramente cômica, afastando-se das habituais histórias de Mickey e Pateta produzidas no período. A comicidade, já explorada por Ramos (2011) aqui fica explícita no momento em que cada trecho da história converte-se em uma piada, seja visual seja textual e, na maior parte das vezes, a fusão de ambas as características que fundam os quadrinhos.

A trama inicia-se com Mickey, que faz as vezes de Mr. Utterson, mas este nome nunca é pronunciado na trama, indo visitar seu amigo Dr. Pateta Jekyll. A partir dos desenhos, podemos perceber a ambientação da trama na Inglaterra vitoriana, com elementos visuais que configuram a época histórica, como as vestimentas das personagens, as fachadas das ruas e até mesmo objetos em cima da mesa de Pateta Jekyll.

Há também a quebra da quarta parede de Brecht, quando Pateta Jekyll faz uma piada sem graça e Mickey Utterson diz que a piada é velha. Pateta responde: "sei disso, mas muitos dos nossos leitores não conhecem". Essa característica persegue toda a coleção Pateta Faz História, onde sempre Mickey ou Pateta em algum momento conversam com o leitor, ou fazem menção de saber que este está lá.

Logo em seguida aparece uma personagem que não há sequer correlato no texto de Stevenson, já anunciando a diferença monstruosa entre ambos os trabalhos: uma senhora entra com um carrinho de bebê com uma flor dentro, pedindo para que o doutor a cure. A cura da flor é o mote para que Jekyll faça sua poção de separação de corpos. Neste ponto a diferença é gritante com o texto clássico. Na obra de Stevenson, Jekyll queria separar o lado bom do lado mau do ser humano, e o fez deliberadamente para conseguir ser uma pessoa melhor, com menos desejos impuros, para aliviar a vida daquilo que era insuportável.

Em ambos os casos, porém, a ideia deu errado: No caso de Stevenson, Jekyll acaba criando outra persona, Mr. Hyde, que, desprovido de senso moral, agredia, insultava, vilipendiava e até matava sem sentir qualquer remorso ou culpa. Quem sentia tudo isso era o Dr. Jekyll que tentou em vão se afastar de seu lado ruim. No caso da Disney, a persona encarnada por Pateta não faz nada de mau. Apenas gosta de dançar e perde a noção do bom senso.

Diferente do Jekyll original, Pateta toma o composto químico por engano, já que a ideia do composto era salvar a flor. Como a bacia onde a personagem guarda 
o composto está furada, gotas da fórmula acabam caindo no seu chá. Assim, depois de tomar o chá, Pateta sai com os amigos e acaba virando o rei da dança em uma discoteca. Ao ganhar o troféu de dançarino da noite, a personagem enfia o troféu na cabeça do apresentador e sai dançando do estabelecimento, mostrando uma personalidade maluca que contrata um taxi para andar duas casas e não o paga. Essa é a primeira forma de maldade que Pateta Hyde faz.

O Hyde original era muito mais maldoso, chegando em determinado ponto da trama a matar por espancamento um parlamentar idoso. A própria descrição do assassinato, onde Mr. Hyde, sem motivo algum, pega a bengala do idoso e começa a espancá-lo e a gargalhar até que ele pare de se mexer é de imensa crueldade. A crueldade de Mr. Hyde, para Stevenson, não tinha limites, afinal, Jekyll, como qualquer ser humano, tenta controlar seu lado mau. Já Hyde não se importa em absoluto com nada que não seja ele próprio.

Este lado egoísta aparece ao contrário na trama com Pateta. Quando Pateta Jekyll volta a si, expulsa um homem e sua macaca do seu apartamento, mesmo com o homem afirmando que Pateta o havia convidado para visita-lo a qualquer hora do dia ou da noite. Na trama, quem convidou o homem foi Pateta Hyde, muito mais alegre e festivo que o contido Dr. Jekyll. Tomando novamente o chá contaminado, Pateta vai à janela e chama novamente o homem e sua macaca para dançar em seu apartamento. Ao entrarem pela porta, um guarda e uma senhora adentram junto, até que a mulher é confundida com a macaca e dá uma bolsada em Pateta Hyde, que volta a ser Pateta Jekyll, expulsando todos de seu apartamento e gerando mais confusão.

Grande parte dessa confusão vem do fato de que Pateta não sabe que está com duas personalidades. Esta talvez seja a maior diferença da trama original, onde Jekyll sabia quando e como transformar-se em Hyde. Tanto que decide não se transformar mais no monstruoso ser do mau. O problema é que de tanto virar Hyde, esta personalidade adquiriu força e conseguiu emergir mesmo sem tomar o composto químico. Ainda assim, Jekyll sabia quando virava Hyde. Pateta não.

Ao se transformar novamente em Pateta Hyde, a personagem começa a fazer maldades. A questão interessante é que para atenuar a história, as coisas ruins que Pateta Hyde faz são apenas irritantes, como pagar o taxi com duas aspirinas e ao ser perseguido pelo motorista pintar um bigode em seu rosto. 
A maior maldade, a equivalente à morte do parlamentar, é subir no topo do Big Ben, famoso relógio londrino e atrasar algumas horas, com o único intuito de fazer as pessoas se atrasarem para o trabalho. Ao se dirigir para casa, a personagem volta a ser Pateta Jekyll e só quando acorda - atrasado - é que descobre que a flor que tomou a fórmula que gera mais uma personalidade passou a ser um ser autônomo, uma flor que pensa, fala, anda e que não quer voltar para seu vaso depois de descobrir um mundo maior fora deste.

Mesmo assim, Pateta Jekyll ainda não consegue entender o que está acontecendo já que continua não sabendo que tanto ele quanto a flor tomaram uma fórmula que faz desenvolver personalidades. Nisso, chegam à sua casa o paciente que ele deveria atender e não foi, o chofer de taxi que foi recompensado pela corrida apenas com duas aspirinas e também um caça talentos em busca da capacidade de Pateta Hyde em dançar. A ironia e a graça está na incapacidade de Pateta Jekyll entender o motivo de aquilo tudo estar acontecendo naquele momento. Todos os envolvidos resolvem bater em Pateta Jekyll, que continua sem entender os motivos das pessoas. Mickey Utterson ainda tenta adivinhar o porquê da conduta do amigo, sugerindo em determinado momento que ele poderia estar trabalhando demais e em outro que ele poderia estar sonâmbulo.

Mesmo assim, não deixam de chegar pessoas à casa de Pateta Jekyll, entre eles o policial que cuidava do Big Ben, cobrando da personagem o fato do relógio ter atrasado duas horas e a dona da flor que virou autônoma.

Neste momento é que a trama é compreendida por Pateta Jekyll e pelas demais personagens. Na hora que a flor decide não ir com a dona dela, começa a falar e a explicar tudo o que acontecera. Essa é a personagem que serve como fio condutor do esclarecimento para os demais. Esta personagem serve, na história da Disney, da mesma forma que as cartas deixadas por Jekyll para Utterson e Lanyon, dois dos melhores amigos do cientista. É por meio delas que o leitor fica sabendo que Dr. Jekyll e Mr. Hyde são as mesmas pessoas. E também é por meio delas que se entende o porquê de Mr. Hyde ser menor, mais jovial e mais leve, além de ter outra aparência física. É com estas cartas também que ficamos sabendo o motivo pelo qual as pessoas sentiam algo estranho e desagradável em Mr. Hyde. Segundo a carta de Dr. Jekyll, todas as pessoas têm seu lado bom e seu lado mau. Menos Mr. Hyde, que era mau puro. 
Depois de resolvido o mistério na história em quadrinhos, vem a solução que fecha a trama: A dona da flor não a deseja mais, mas o caçador de talentos acha uma flor falante mais interessante do que um excelente dançarino. Ao tentar jogar a poção fora, Pateta Jekyll a derrama em cima do empresário, que, num ato inesperado e nonsense típico das aventuras da coleção Pateta Faz História, sai voando pela janela. Tudo volta ao normal, Pateta Jekyll para de dançar e a flor volta a ser uma planta comum. Mas ao pedirem o jornal, uma semana depois, descobrem que o caça talentos voador é o homem mais famoso da Itália, depois de ter voado da casa de Pateta Jekyll, em Londres, até Roma, na Itália.

Já o final da trama de Stevenson é bem mais pesado. Dr. Jekyll, depois de decidir não tomar mais o elixir que o transformava em Mr. Hyde, começou a sofrer a transformação mesmo sem beber nada. E então usava o mesmo pó branco para tentar conter a presença vilanesca dentro de si. Não adiantou, e Mr. Hyde começava a se transformar mesmo com Dr. Jekyll tentando ao máximo segurar seu lado mau dentro de si. A partir daí, se Jekyll se descuidasse, ou mesmo se dormisse, virava Hyde.

Ao mesmo tempo, acaba o estoque de pó branco e ao comprar mais, percebe que aquele anterior tinha alguma impureza que dava esta transformação como espécie de efeito colateral. Nisso, Dr. Jekyll escreve as cartas como último ato sendo Dr. Jekyll Ele termina a carta dizendo que a partir de agora não existiria mais Dr. Jekyll, apenas Mr. Hyde. Quando Utterson e o criado de Jekyll arrombam a porta de seu quarto percebem um Mr. Hyde agonizando, com o pó branco nas mãos, tentando voltar a ser Dr. Jekyll.

Assim termina a história, com um aspecto denso e até moralista, tal qual Frankenstein de Mary Shelley ou O Homem Invisível de H. G. Wells. O lado mau, perverso do ser humano pode ser maior do que o lado bom. E o cientista que busca desesperadamente pela solução de um problema não pode fazê-lo sem se conscientizar do aspecto humano, ético de seus experimentos. 


\section{CONCLUSÃO}

Por fim, podemos perceber que a paráfrase dos estúdios Disney à distopia criada por Stevenson foi muito acertada para seus propósitos, já que pega a ideia central da trama mas retira toda a parte de terror e moralismo existente no texto original, ao mesmo tempo em que agrega aspectos humorísticos típicos das histórias de Mickey e sua turma. As mudanças da personagem de Pateta Jekyll/Hyde têm como finalidade principal fazer rir, os alívios cômicos, as cenas e as situações absurdas criadas apenas na versão com Pateta tornam a absorção do clássico de Stevenson agradável, divertida e em muitos casos pode vir a ser o vetor necessário que levará o leitor a ter contato com a obra original.

\section{REFERÊNCIAS BIBLIOGRÁFICAS}

CAVALCANTI. Ionaldo A. O mundo dos quadrinhos. São Paulo: Símbolo, 1977.

COSTA, Angela Marques; SCHWARCZ, Lilia Moritz. 1890-1914: No tempo das Certezas, São Paulo: Cia. das Letras, 2007.

IACHTECHEN, Fábio Luciano. Gênero Utópico e o Discurso Científico na Ficção De H. G. Wells. Dissertação de Mestrado: PPGTE, UTFPR, 2008.

Inducks.org. Cal Howard Bio. Disponível em:

<http://coa.inducks.org/creator.php?c=Cho>. Acesso em: 10 de julho de 2013.

PESAVENTO, Sandra Jathay. Exposições Universais. São Paulo: Cultrix, 1997.

RAMOS, Paulo. Faces do Humor. São Paulo: Zarabatana, 2011.

RIBEIRO, Rivaldo. Pateta faz História vol. 18 - Rei Midas e o Médico e o Monstro. São Paulo: Abril, 2011.

SUPPIA, Alfredo Luiz. O Médico e o Monstro: Há 120 anos, uma história inspiradora. Revista Ciência e Cultura vol. 57 nº 4 São Paulo: Unicamp, 2005. Disponível em <http://cienciaecultura.bvs.br/scielo.php?pid=S000967252005000400032\&script=sci_ arttext>. Acesso em 10 de julho de 2013. 